\title{
Optimization of efficiency for power system using three phase AC to AC matrix converter with the algorithm of fuzzy controller
}

\author{
Hassan Farahan Rashag \\ Department of Electronic Techniques, Technical Institute of Babylon, Al- Furat Al-Awsat Technical University, Iraq
}

\section{Article Info}

Article history:

Received Feb 9, 2019

Revised Apr 25, 2019

Accepted May 12, 2019

\section{Keywords:}

Clarke transformation

FLC

Inverse park transformation

Matrix converter MC

RLC load

\begin{abstract}
This paper suggested a new contribution of three phase AC to AC matrix converter MC via fuzzy logic controller FLC to enhance the whole system. However, the weakness of matrix converter is that the input- output voltage transfer is control to $87 \%$ for input and output waveform. Also, matrix converter is more sensitive to the trouble of input voltage which deteriorates the system performance. To overcome these problems, and to improve the efficiency of system, FLC with matrix converter is proposed to minimize the sensitivity to the load, and to increase voltage transfer. In this paper the currents a,b,c are converted to alpha and beta current via Clarke transformation. In this method two FLC are used. The error (between alpha current and reference current) (e) and the change of this error (de) will apply to first FLC. The output of FLC is actual alpha current. In the other hand, the error of beta current and the change of error are also passes through the second FLC to produce the actual beta current. The actual alpha and beta current is converted to direct and quadrature $\mathrm{d}-\mathrm{q}$ current by park transformation. The d-q current is converted to $(a, b, c)$ out currents by inverse park transformation, the results of this method express that the matrix converter with FLC is more capable, high accuracy with better efficiency as compared with conventional matrix converter system.
\end{abstract}

Copyright $@ 2019$ Institute of Advanced Engineering and Science. All rights reserved.

\section{Corresponding Author:}

Hassan Farahan Rashag,

Department of Electronic Techniques,

Technical Institute of Babylon, Al- Furat Al-Awsat Technical University,

54003, Kufa, Najaf Governarate, Iraq.

Email: hassan_rashag@yahoo.com

\section{INTRODUCTION}

The three phase matrix converter is the most exciting associates of the power system that converted the $\mathrm{AC}$ to $\mathrm{AC}$ converter. MC presented in 1976 and continuing to enhance after widespread high-frequency switching approach in 1980 [1-2]. Matrix converters have conventional significant devotion in the current years. MC develops a good substitute and more better than the classical pulse width modulation [3-4]. Additionally, the MC permits a compacted design because of the absence of dc-link for storage of energy [5]. Many authors proposed methods to minimize the fluctuating of the input voltages distortion [7-10]. The control systems is applied to matrix converter to enhance the system and to diminution the current distortion based on space vector modulation [11-15]. In [16] proposed FLC with MC to decrease total harmonic distortion of current and voltage. 


\section{PROPOSED METHOD BASED ON FUZZY LOGIC CONTROLLER}

This proposed method is executed by using Simulink Matlab with Toolbox and Simpower system. In order to improve the system dynamic, two FLC are used. The types of membership are Gaussian membership function. In this method, the main reason for using FLC is the mathematical model of matrix converter is very complicated and the FLC no need mathematical model. Furthermore, the rules of FLC depend on human experts. In this proposed method the three phase currents a, b, c are converted to alpha $(\alpha)$ and beta $(\beta)$ current by Clarke transformation in order to mitigate the complexity of system. The Simulink of proposed FLC with whole system and Simulink of matrix converter MC are shown in figures 1 , and 2 respectively.

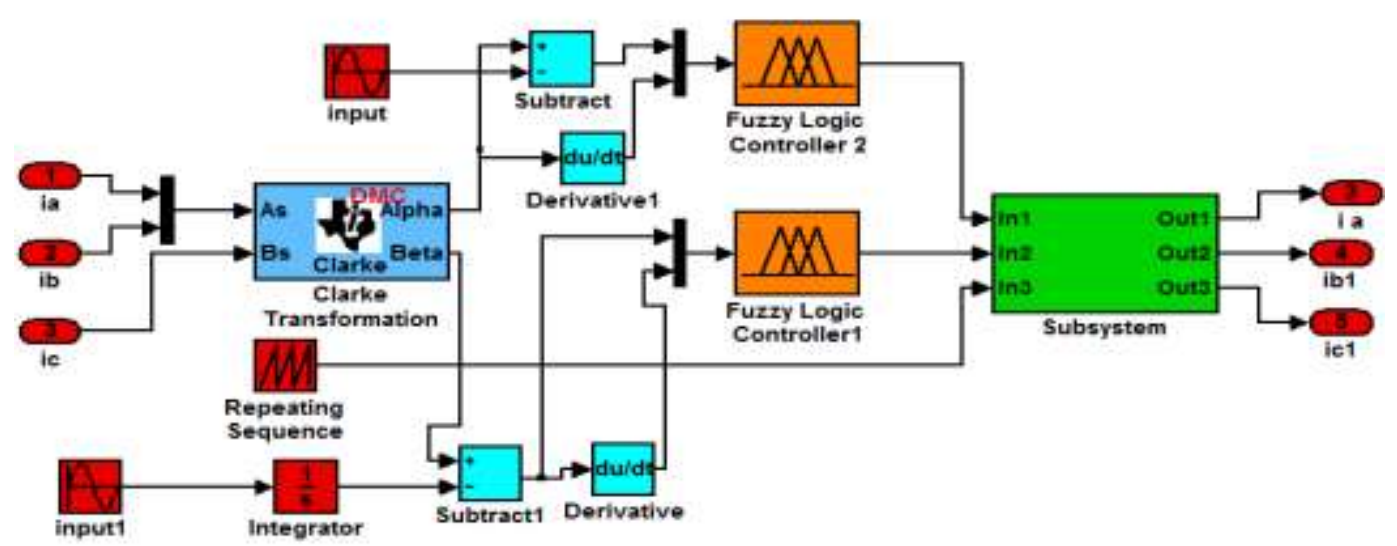

Figure 1. The Simulink of proposed FLC with MC

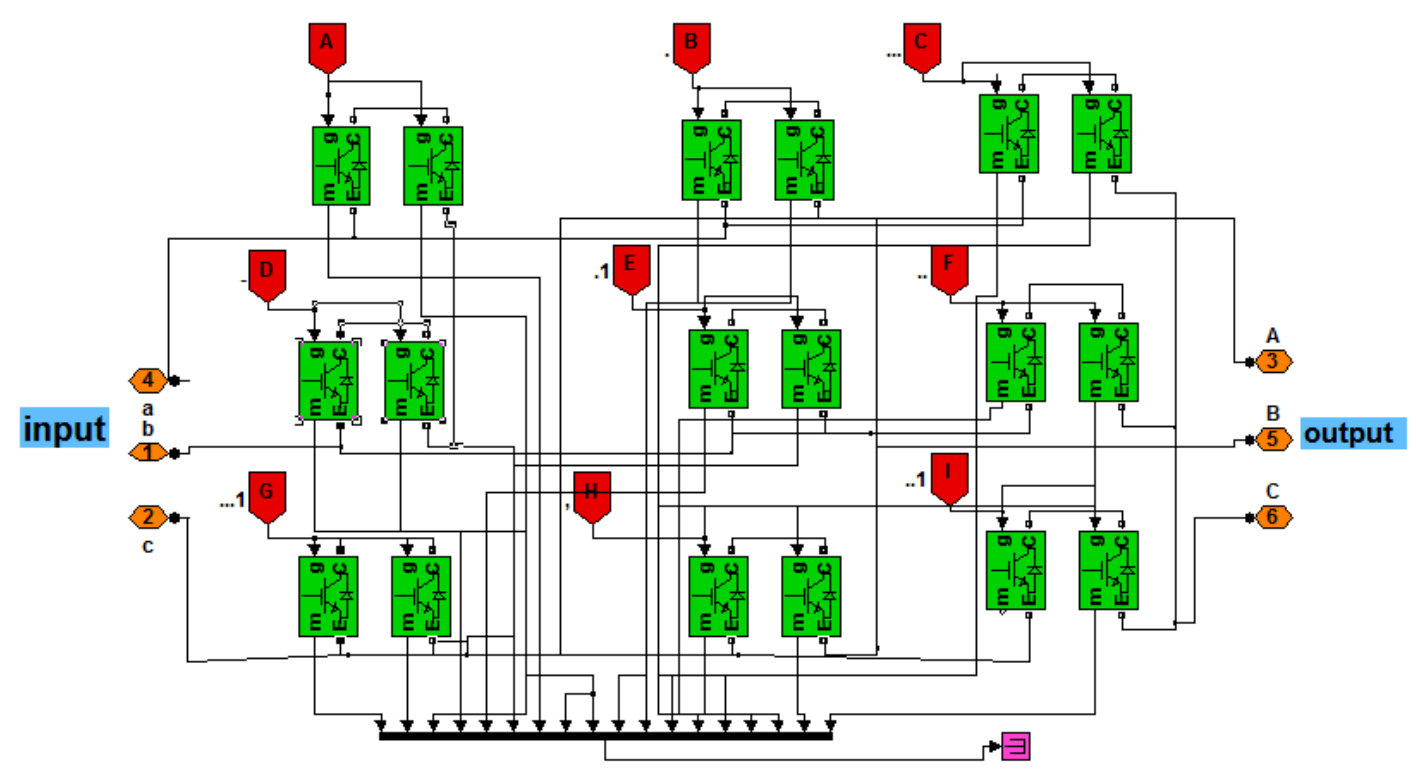

Figure 2. The Simulink of matrix converter

The diagram of fuzzy logic control with its membership function is shown in figure 3 . The Gaussians membership functions are used for inputs of FLC but the triangular membership function is used for output of FLC. 


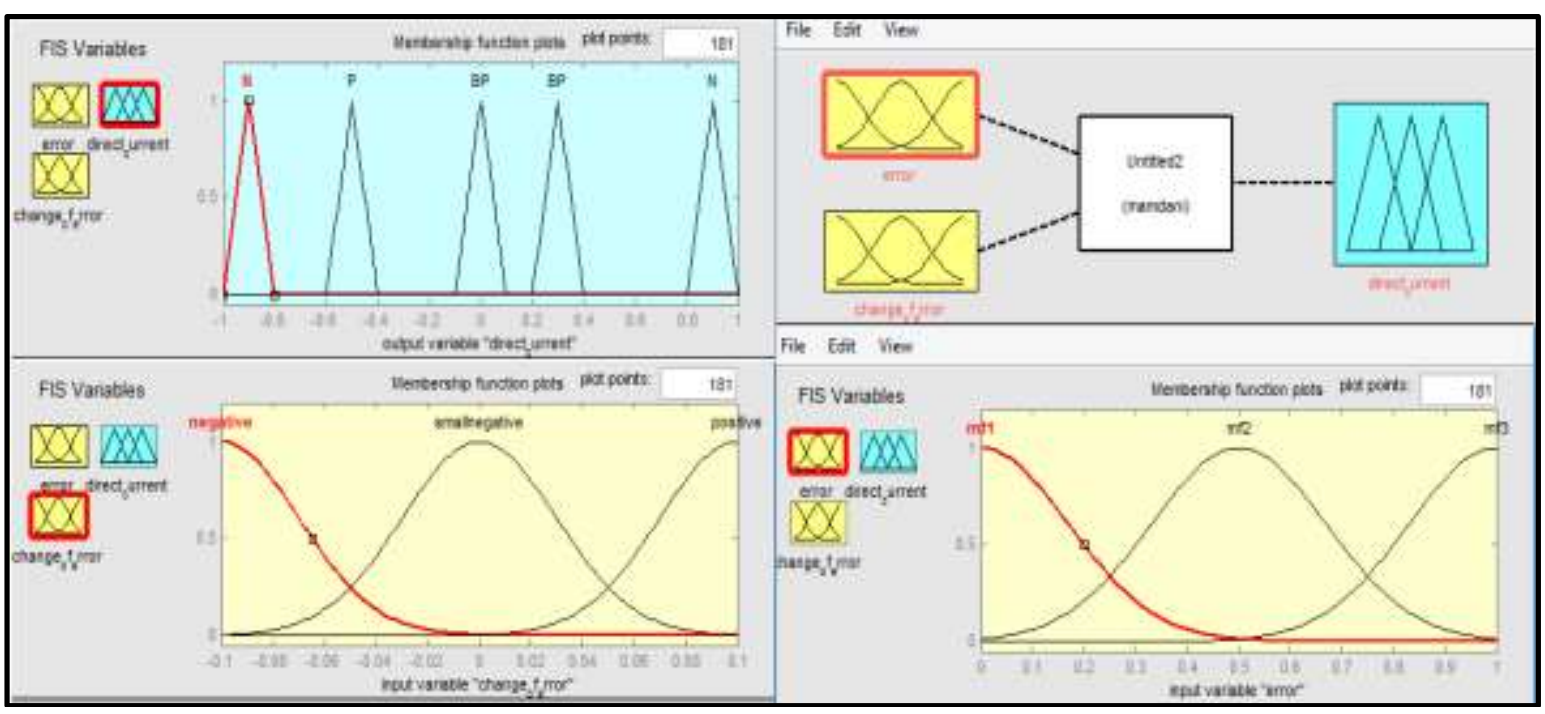

Figure 3. The scheme of FLC with its membership function

\section{SIMULATION RESULTS AND DISCUSSION}

In Figure 4, the output voltage of matrix converter MC based on FLC is $400 \mathrm{~V}$ which is equal to input voltage. In contrast, the output voltage of conventional MC is $200 \mathrm{~V}$ which decrease the performance of system. The output current with conventional MC is distorted from peak to peak while the current with FLC is more smooth and free of distortion as shown in Figure 5.

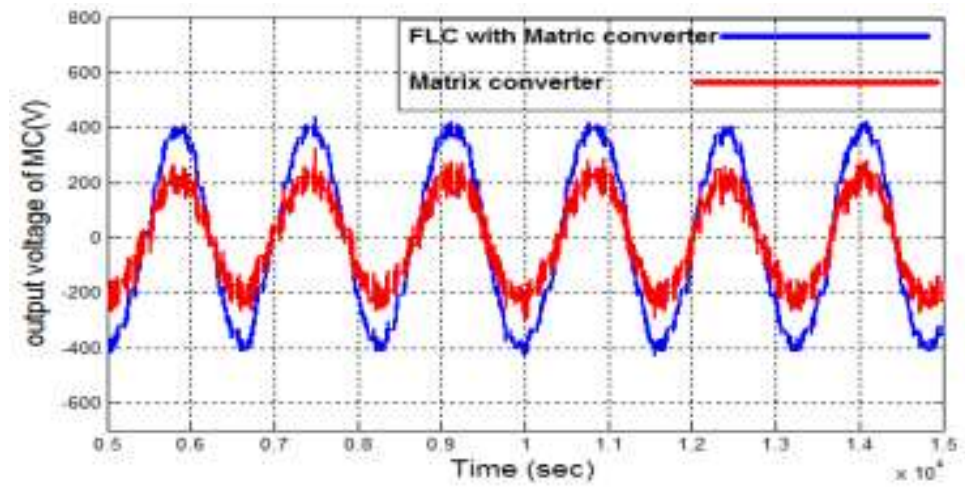

Figure 4. Output voltage comparison

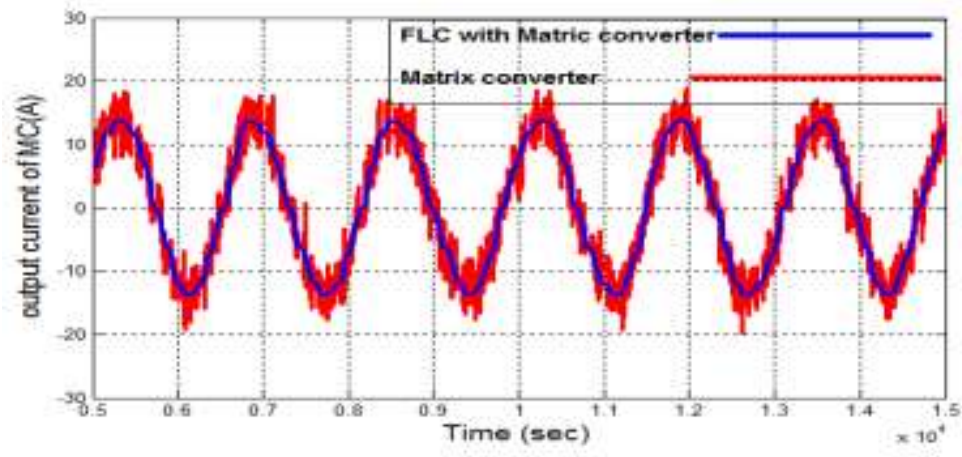

Figure 5. Comparison of output current 
Figure 6 shows the voltage at the output of IGBT transistors of MC which is almost $400 \mathrm{~V}$ and approximately has low distortion because of switching losses. In Figure 7, the output voltage at RLC load based on FLC is more sequence and smooth which is free of harmonics.

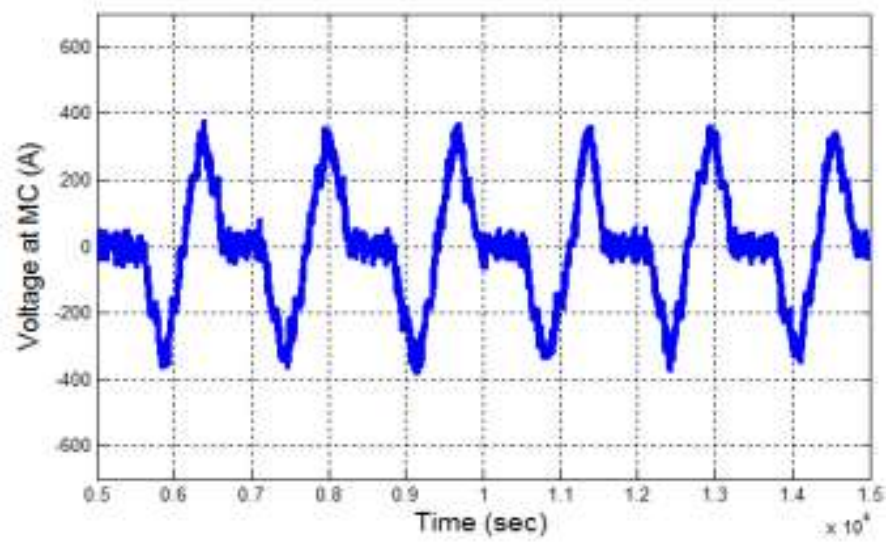

Figure 6. Voltage at IGBT transistor

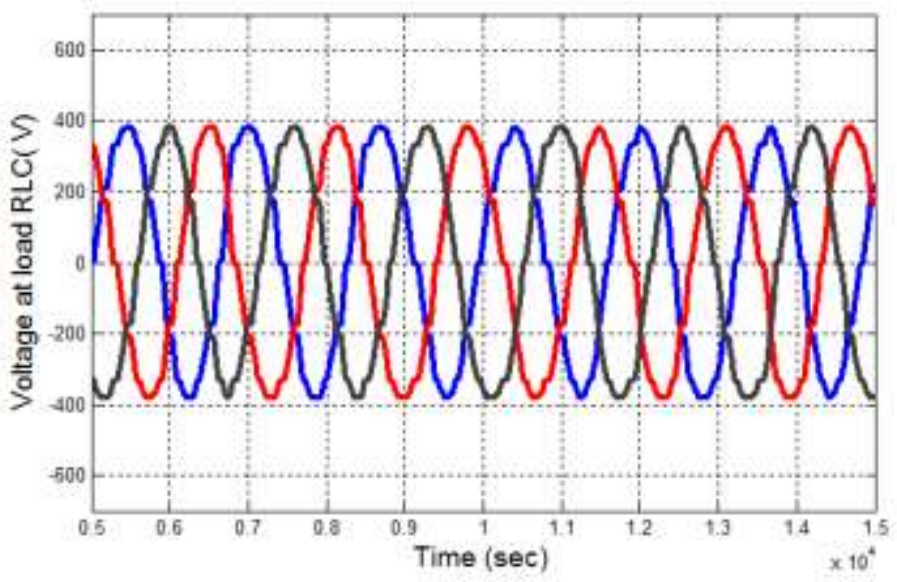

Figure 7. Output voltage of RLC load based on proposed FLC

\section{CONCLUSION}

In this paper, to improve the power system techniques, it is important to investigation a new innovative solution. Here, this proposed method having three phase AC to AC matrix converter MC with FLC to improve system performance. In addition, the waveform of current and voltage are free of distortion which lead to decrease the harmonics through FLC as results the efficiency of system is optimized. The results of this new approach based on fuzzy control strategy with MC exhibits that the system is more robust and improved the efficiency by reducing the fluctuating of current and voltage waveform.

\section{REFERENCES}

[1] M. Venturini, "A New Sine Wave in Sine Wave out, Conversion Technique Which Eliminates Reactive Elements," Proceedings of Powercon 7, pp. E3/1-E3/15, 1980.

[2] A. Alesina, M. Venturini, "Analysis and Design of Optimum Amplitude Nine Switch Direct AC-AC Converters," IEEE Trans. Power Electron., vol. 4, no.1, pp. 101-112, Jan. 1989.

[3] L. Huber, D. Borojevic, "Space Vector Modulated Three-Phase to Three-Phase Matrix Converter with Input Power Factor Correction," IEEE Trans. Ind. Applicat., vol. 31, no. 6, pp. 1234-1246, Nov./Dec. 1995.

[4] D. Casadei, G. Serra and A. Tani, "Reduction of the Input Current Harmonic Content in Matrix Converters under Input /Output Unbalance," IEEE Trans. Ind. Applicat., vol. 45, no. 3, pp. 401-409, June 1998. 
[5] P.W. Wheeler, J. Rodriguez, J.C. Clare, et al., "Matrix Converters: a Technology Review," IEEE Trans. Ind. Electron., vol. 49, no.2, pp.276-288, April 2002.

[6] H. Karaca, R. Akkaya, "A Matrix Converter Controlled with the Optimum Amplitude-Direct Transfer Function Approach," 6th International Conference on Electrical Engineering ICEENG 2008, May 2008.

[7] P. Nielsen, F. Blaabjerg, J. K. Pedersen, "Space Vector Modulated Matrix Converter with Minimized Number of Switchings and a Feedforward Compensation of Input Voltage Unbalance," IEEEPEDES'96, vol. 2, pp. 833-839, 1996.

[8] P. Nielsen, D. Casadei, G. Serra, A. Tani, "Evaluation of the Input Current Quality by Three Modulation Strategies for SVM Controlled Matrix Converters with Input Voltage Unbalance," IEEE-PEDES'96, vol. 2, pp. 794-800, 1996.

[9] K. Sun, D. Zhou, L. Huang, K. Matsuse, "Compensation Control of Matrix Converter Fed Induction Motor Drive under Abnormal Input Voltage Conditions," IEEE-IAS'04, pp. 623-630, 2004.

[10] M. E. O. Filho, E. R. Filho, K. E. B. Quindere, J. R. Gazoli, "A Simple Current Control for Matrix Converter," IEEE-International Symposium on Industrial Electronics, pp. 2090-2094, 2006.

[11] L. Huber and D. Borojevic, "Space vector modulator for forced commutated cycloconverters," in Conf. Rec. IEEEIAS Annu. Meeting, 1989, pp. 871-876.

[12] L. Huber, D. Borojevic, and N. Burany, "Analysis design and implementation of the space-vector modulator for forced-commutated cycloconvertors," Proc. Inst. Elect. Eng., pt. B, vol. 139, no. 2, pp. 103-113, Mar. 1992.

[13] L. Huber, D. Borojevic, X. Zhuang, and F. Lee, "Design and implementation of a three-phase to three-phase matrix converter with input power factor correction," in Proc. IEEE APEC'93, 1993, pp. 860-865.

[14] L. Huber, D. Borojevic, and N. Burany, "Digital implementation of the space vector modulator for forced commutated cycloconverters," in Proc. IEE PEVD Conf., 1990, pp. 63-65.

[15] L. Huber and D. Borojevic, "Space vector modulated three phase to three phase matrix converter with input power factor correction," IEEE Trans. Ind. Applicat., vol. 31, pp. 1234-1246, Nov./Dec. 1995.

[16] O. Hemakesavulu, T. Brahmananda, "Improvement of THD Using Fuzzy Logic Based PWM Modulation Technique in Matrix Converter Fed AC Drives," International Journal of Engineering Sciences \& Research Technology, vol. 6, no. 3, pp. 29-34, 2017. 